\title{
A doutrina de Freud
}

Trabalho lido na Sociedade Arnaldo Vieira de Carvalho, em 10 de Junho de 1927, pelo dr. José de Almeida Camargo.

$\mathbf{N}^{\mathrm{a}}$

ÃO é dificil descobrir em multiplos aspectos da vida moderna, influencias multiplas da theoria de Freud.

O material de que me utilizei para tal constatação é bastante numeroso e comprehende, em sua maioria, as mais variadas manifestações da vida artistica contemporanea, desde Rimbaud, Cézanne e os primeiros vagidos do dadaismo até a expressão rapida, cinemotographica, desportiva, simultanea, da hora actual.

Acredito que o estudo do que chamamos a "nossa inquietação" deve ser precedido de uma exposição da theoria psychoanalytica de Freud.

E' o que pretendo fazer hoje, valendo-me de um pequeno trabalho meu já publicado ha mais de um anno e que não chegou ao conhecimento desta sociedade.

Posteriormente, entrarei nas applicações da theoria que mais me interessaram, e que irão constituir a finalidade desta exposição.

A doutrina de Freud (que preferimos chamar theoria), originada dentro das sciencias medicas, a proposito de uma entidade morbida-a hysteria-de estudo apenas accessivel á mentalidade de um reduzido numero de pessoas, alargou o seu ambito de tal maneira que seu conhecimento escapa ao tão só dominio da especialidade.

Simples explicação medica, a principio, nascida no espaço estreito de um hospital, sobre um caso clinico definido, foi alargando successivamente o seu campo de extensão, passando a abraçar a psychologia pathologica, a psychologia normal e os proprios dominios mais largos da esthetica e da philosophia.

Para que se avalie de seu grande alcance, baste dizer-se que a Psychologia era definida - ao menos pela maioria dos entendidos como a "sciencia dos phenomenos de consciencia" Ora, a psychologia de Freud mostra-nos que os phenomenos de consciencia, os phenomenos que se passam com nosso conhecimento actual, representam a parte menor do mechanismo psychico. Sobre representarem a parte minima, representam a de maior insignificancia. 
O inconsciente é que é o grande campo da psyche. Os actos conscientes são, apenas, uma attitude, occasional, na serie do dynamismo psychico.

A theoria de Freud, pela sua só universalidade de applicação, mostra-se uma theoria scientifica, um methodo experimental e uma therapeutica racional.

Nem mais ella exige para ser tomada em consideração - "o minimo a que tem direito" - na opinião de Claparéde. (1).

Não ha duvida que se trata de uma theoria. Mas uma theoria que tem razão de existencia emquanto não lhe appareça uma substituta.

E uma theoria scientifica. Nem só o que é verificado é scientifico, mas tambem o que é possivel de verificar-se, diz em alguma parte Ingenieros.

Além disso, quando não bastassem taes titulos de originalidade e de largueza, baste, como motivo de exposição, o grande valor didacta da theoria.

Freud focaliza o estado da psychologia actual e dá-lhe uma orientação e uma attitude novas.

Já se pode falar, sem exagero, como já se falou, em Psychologia antes e depois de Freud. Já se conhecem seus multiplos pontos de contact̃o com os modernos processos de expressão artistica. Já se percebem novos horizontes de educação. Já se estabelecem as bases de uma critica scientifica.

Sem falar no resultado therapeutico.

Acreditamos que o conhecimento da psychoanalyse seja de grande utilidade. Quando não o fosse pelas razões da sua importancia, servirá, ao menos, para base de uma critica, senão scientifica em rigôr (faltam-nos observações) ao menos honesta-o minimo que pode exigir o trabalho do professor de Vienna, que poucos conhecem e que muitos desprezam.

Sem ter a pretensão de dar um cunho pessoal á theoria, resolvemos expô-la, simplesmente, sem grandes citações e abundancia de detalhes, collimando apenas o que desejamos-o preparo para uma exposição posterior.

O eminente creador do pan-sexualismo não tem o desejo de ser original. Nem elle emprega este termo, como veremos adiante, na accepção vulgar.

\footnotetext{
(1)-Intrcducção ás "Cinq leçons sur la psychnalyse". de Sigm. Freud Paris-1923,
} 
Bem que apresentando faces verdadeiramente desconhecidas até hoje, suas affirmações fundamentaes se encontram, quando não explicitamente affirmadas, implicitamente suspeitadas.

Veja-se, p. exp., a theoria do inconsciente: o sub-liminal de Myers (não sublimal, como traduziu um notavel critico indigena) é o inconsciente de Freud. A propria psychologia classica affirma o inconsciente; se o não dissesse francamente, lembra-o o termo "consciente"

Freud, repetimo-lo, não quer ser original. Basta-lhe o muito de ter focalizado da maneira mais clara, mais logica e mais scientifica, todo o problema psychologco. Nenhuma theoria psychologica até hoje, abarcou todos os phenomenos de ordem mental, como a de Freud.

Talvez, com a affirmação da não originalidade da theoria, se satisfaçam as velleidades criticas dos que se dizem criticos, esquecendo o sentido nobre do termo. Em geral, a maioria dos criticos, chamados commumente avisados, subtis e eruditos, contenta-se em descobrir precursores, dos quaes nunca se lembraria se não tivesse a ideia nova a aguçar-lhe o appetite destruidor.

Jules Sageret, em livro recente, (2) estuda os pontos de contacto entre as theorias de Bergson, Le Dantec, Einstein e Rosny Ainé, concluindo por uma revolução philosophica dellas oriunda, já que se identificam em seu aspecto dynamico, negativista do presente, das cousas formadas, das realizadas e affirmativas do evoluir, do élan, do transformar-se.

Sageret lembra-se de Einstein. Não tem, portanto, a prevenção franceza de que a sciencia deve ter um cunho nacionalista.

Entretanto, esqueceu Freud.

O creador da psychoanalyse, porém, deve, pela sua theoria do inconsciente dynamico, filiar-se aos quatro renovadores do pensamento philosophico moderno. se os criticos permittirem uma attitude philosophica originada na sciencia.

\section{A THEORIA DE FREUD}

tem o nome de psychoanalyse. Mas estes termo ainda indica um processo de exploração mental e um processo therapeutico, ambos creados por Freud.

\section{O INCONSCIENTE}

A base da theoria vem a ser a concepção do inconsciente, concepção que já existia, como já se disse. Mas na Psychologia Classica, o inconscente era o depositorio em que accumulavam os processos mentaes, á espera de um accesso na consciencia.

(2)—“La revolution philosophique et la sciense"-F. Alcan, Paris. 
Era, portanto, estatico.

O que o differençava do consciente era, apenas, uma questão de attitude, de detalhe, um ponto de vista subjectivo: conscientes os phenomenos que se passavam com conhecimento actual do observador; inconscientes os que dormitavam á espera de um lugar no campo da consciencia, susceptiveis de se tornarem conscientes, como os primeiros, inconscientes apenas na occasião.

Para Freud, entretanto, deixa de haver a differença entre consciencia e inconsciencia. Ha, somente, actos psychicos. A distincção que se fazia, impunha-se só ao observador. Classificação pessoal.

$\mathrm{Na}$ psychonalyse os processos psychicos são em sua quasi totalidade inconscientes.

Quão longe vamos dos que, abusando da introspecção, diziam da psychologia: sciencia que estuda os estados de consciencia emquanto estados de consciencia"!

$\mathrm{O}$ inconsciente é, na theoria de Freud, o grande dominio psychico. E é absolutamente dynamico.

Os processos mentaes não dormitam ahi, estaticamente, esperando um accesso no campo da consciencia. Antes, vivem uma vida dynamica intensa, em que as tendencias instinctivas do ser procuram manifestar-se, dando origem a verdadeiros conflictos mentaes.

Freud divide o inconsciente em preconsciente e inconsciente propriamente dito.

$\mathrm{O}$ primeiro comprehende os processos mentaes que se podem facilmente tornar conscientes: são as lembranças que a memoria pode evocar, trazendo-as á luz clara da consciencia. O segundo é constituido pelas tendencias instinctivas, pelo lastro hereditario, pelos processos mentaes, emfim, inacessiveis á consciencia e que, conservando a potencialidade que os anima, procuram manifestar-se, já symbolicos, como nos sonhos, já despercebidos, como nos actos machinaes, já como symptomas, nas nevroses.

Resalta-assim, desta exposição, como o mostra José Crespo, o caracter indestructivel dos processos mentaes. Os conhecimentos, por mais superficialmente que sejam adquiridos, não se perdem. Vivem no inconsciente uma grande vida dynamica, esperando uma occasião em que possam manifestar-se.

Repelidos, na sua tentativa, por forças repressivas, nem por isso se calam. Animados da força que possuem aproveitam-se (passe a forma anthropomorphica de expressão, necessaria ao entendimento) - das ocasiões favoraveis: o somno, a embriaguez, a distracção, favorem-lhes a sahida, illudindo as forças repressivas por meio de symbolismo.

Antes de passarmos além, caiba aqui uma explicação, que não se dirige, evidentemente, a vós, mas que tem razão de ser quando se sou- 
ber que eu destinarei este trabalho á qualquer columna de divulgação scientifica offerecida a leigos.

Quando Freud mostra a separação entre consciencia e inconsciencia, e divide esta em sub-consciencia e inconsciencia propriamente dita, entenda-se que essas separações não se localizam, não teem toporgraphia, não existem no espaço.

No psychismo só existem actos psychicos: estes são inconscientes ou sub-conscientes, podendo os ultimos tornarem-se, occasionalmente, conscientes.

Mostra esta resalva que todas as comparações (e são muitas) que se fazem desses estados e a propria linguagem desta exposição, só têm por fim dar uma apparencia material á serie e successão dos phenomenos mentaes, tornando-os, assim, mais facilmente comprehensiveis.

\section{O CONTEƯDO CONSCIENTE E O CONTEÚDO INCONSCIENTE}

$\mathrm{Na}$ crença, a consciencia e a inconsciencia são bastante semelhantes e tendem a confundir-se a medida que mais nos acercamos do começo da vida (José Crespo). (3)

O predominio é, então, completo dos impulsos, tendencias e instinctos, dominando o principio egoista da satisfacção pessoal.

$\mathrm{A}^{\prime}$ medida que $\mathrm{o}$ individuo se desenvolve e que seu egoismo se vae limitando pelo egoismo dos demais, o conteúdo consciente se vae formando exclusivamente á custa dos impulsos, tendencias e instinctos modificados pela experiencia social.

Essas modificações tendem á adaptação do individuo ao meio, que não permitte amplas expansões egoisticas.

Acontece, então, que as tendencias, impulsos e instinctos essencialmente egoistas, não podendo manifestar-se na consciencia, por imposição do meio social, refugiam-se na inconsciencia, na espera de occasião mais favoravel para "achar expressão em nossa conducta"

O principio que domina o inconsciente é, portanto, o affectivo, de satisfaç̧ão do egoismo - ao qual Freud chama de principio do prazer. $\mathrm{Na}$ consciencia domina a razão, unica compativel com a vida social, - denominada por Freud, - principio de realidade.

Apparece-nos assim, a consciencia, como appareceu a Max Nordau, a representação que a collectividade tem em cada individuo. Este só existe, de facto, na inconsciencia, onde moram os seus impulsos de satisfacção pessoal.

$\mathrm{O}$ individuo consciente não será, portanto, o individuo: é o individuo limitado, modificado, impessoal, feito sob a encommenda de todos os individuos.

(3)-Psicoanálitis-Revista de Filosofia-Buencs Aires, anno X, n. 2. 


\section{REPRESSÃO-CENSURA-SUBLIMAÇÃO-COMPLEXO}

Como já se disse, á medida que o invidiuo cresce em sociedade, seus impulsos egoistas se vão modificando, limitando, sofreando, á custa dos processos sociaes de educação, temor, religioso, imposições sociaes em summa.

Dois processos se passam no psychismo por influencia destes novos elementos: a repressão e a censura.

Qualquer impulso que fuja ás conveniencias sociaes e que queira expandir-se na consciencia, submette-se á repressão, será recalcado na inconsciencia, onde vae constituir, com outras tendencias que sofreram o mesmo processo e que se associam pelo mesmo movel affectivo o que Freud chama Complexo.

A censura escolhe os elementos que podem vir á consciencia sem damno social. $\mathrm{Ha}$, desta maneira, um processo psychico de seleç̧ão que só permitte a expansão consciente de alguns elementos psychicos, com prejuizo de outros, nocivos á adaptação á sociedade e que, nenı por serem recalcados, deixam de procurar transpor o limiar da consciencia, indirectamente, illudindo a censura.

Vemos, portanto, uma grande lucta psychica, causando symptomas de nevrose, entre a censura, seleccionadora repressora, e os elementos affectivos, inconscientes, recalcados.

Estes ultimos, ficou dito atraz, procuram objectivar-se na conducta do individuo, já illudindo a censura, como nos sonhos, já por um processo especial, que traz um pouco de equilibrio á lucta entre as forças antagonistas: a sublimação. Pela sublimação, desvia-se o complexo recalcado do seu verdadeiro movel affectivo, indo applicar-se em um motivo superior onde acha expressão e applicação a sua affectividade.

A arte não seria mais que a consequencia de um mechanismo sublimativo.

Veja-se o exemplo de Wilde. Na historia de sua vida, retirados mesmo os detalhes que a ignorancia ambiente soube inventar, percebe-se a predominancia do narcisismo, forma que emprega Freud quando fala do amor proprio e do instincto de consideração pessoal. Este instincto, que não poude achar expansão na sociedade, principalmente na sociedade puritana de seu tempo, recalcado por imposição della, achou sua expansão na arte, sublimando-se, deslocando a affectividade para um motivo superior.

Não seria difficil descobrir Wilde em Dorian Gray

Um exemplo de complexo:

E' o chamado complexo de Edipo.

Para a theoria de Freud o amor filial primitivamente, nas creanças, de signifıcação sexual, vae perdendo com a educação e a noção 
do incesto o aspecto erotico primitivo para assumir a tc. maculada de amor puro que o filho nutre pela sua mãe.

Entretanto, Freud descobre em numerosas observações o $c x-$ plexo recalcado, procurando expandir-se, illudindo a censura, quer como symptomas de psychonevrose, quer, mais disfarçadamente, pricurando no rosto das namoradas a imagem da primeira mulher que conheceu.

Esse complexo, dos mais frequentemente encontrados por Freua e seus discipulos é denominado complexo de Edipo.

Como se sabe, Edipo, encarnação da má sorte, matou seu proprio pae e casou-se com sua propria mãe.

Aliás, com pequenas variantes, o mesmo complexo incestuoso predomina no Hamleto.

Como se pode prever, é este um dos pontos mais atacados da theoria de Vienna, que se imiscue assim nas mais delicadas regiões da alma humana.

Eu me recordo bem que a primeira noticia que tivemos da theoria psychoanalytica, relatada pelo Prof. Franco da Rocha, foi seguida de uma reclamação das directoras de uma revista feminina de São Paulo, clamando em nome das mães brasileiras.

Eu passo adiante.

\section{A LIBIDO E O PAN-SEXUALISMO}

Depois de descoberto o seu methodo de exploração mental a psychoanalyse - methodo que usa dos sonhos, lapsos, esquecimentos, como de uma semeiologia mental, não foi dificil a Freud chegar á sua concepção de libido e de pan-sexualismo.

Pela psychoanalyse, Freud e seus discipulos chegaram sempre, nos nevroticos, a filiar o processo symptomatico a um complexo inconsciente de componentes eroticos.

Para esse resultado a resistencia encontrada foi enorme. A resistencia opposta pelo paciente á penetração do analysta no seu inconsciente, sempre inconfessavel, era um obstaculo a transpor. Psychoanalyses minuciosas, repetidas, pacientes, encalhavam - ás vezes em acontecimentos de origem traumatica.

Entretanto, com o aperfeiçoamento do methodo, sempre foi possivel, sem forçar as conclusões, ir além desses acontecimentos banaes, incapazes, por si sós, de explicar o numero e a intensidade dos symptomas.

A psychoanalyse, levada então ao inconsciente mais remoto descobria ahi complexos eroticos, causadores dos symptomas, na idade a mais afastado do paciente - na infancia.

Descoberto, desse modo, o pansexualismo, vejamos a concepção que Freud faz da libido. 
Prazer sexuaı não teı para a ıscola psychoanalytica o significado restricto que hoje lhe é dacio. Antes, extranha essa restricção, quando maior largueza deveria ter.

Esse prazer já existe na infancia. A libido não penetra no homem - como di-lo Freud e cortam-no os Evangelhos - o diabo penetra no corpo.

E' forçoso admittir que já exista nos primeiros annos.

E existe. Mas sob forma diffusa, espalhada, dispersa, produzindo pequenas satisfaç̧ões agradaveis.

Nos primeiros annos da vida, o individuo satisfa-se: periodo de auto eroitsmo; depois, a libido desloca-se para o sexo opposto. Ao mesmo tempo as tendencias sexuaes, diffusas, reunem-se, sujeitando-se e localizando-se.

A persistencia, na idade adulta, de uma tendencia (ou mais) que se não reuniu ás outras, constitue a perversão. A nevrose, ao contrario, resulta da acção exercida na dynamica psychica por uma tendencia, recalcada no inconsciente e que a elle se soube impôr.

\section{FIXAÇÃO—KEGRESSÃO}

A suboräinação do principio do prazer ao principio da realidade opera-se lentamente, evolutivamente, no correr da vida individual.

Entretanto, os elementos instinctivos, inionscientes, podem, no decorrer dessa evolução sofrer dois processos que vão determinar attitudes anormaes: a fixação e a regressão.

Pelo primeiro processo - de fixação - os elementos instinctivos, primarios sofrem, no correr da evolução e por influencia de causas varias, externas, uma parada em um ou mais de seus componentes, persistindo, portanto na idade adulta.

Pela regressão, esses mesmos elementos, chegados á sua maturaçâo, involuem, pelas mesmas causas, voltando á situação primitiva.

Veja-se um exemplo de fixação que esclarece tambem o $2 .^{\circ}$ processo:

O instincto sexual, nas creanças, não se acha localizado como no adulto. Vive diffuso, permittindo as satisfações sexuaes as mais diversas, só se reunindo no decorrer da evolução para formar, no adulto, a esphera sexual delimitada.

A zona erogena buccal, por exemplo, que encontra satisfacção nas creanças no proprio acto de mamar, pode, não perder o seu caracter sexual, fixando-se no decorrer evolutivo, afastando-se dos outros componentes eroticos, para attingir na idade adulta um tal desenvolvimento e uma tal importancia que explicam o seu uso desabusado da parte de tanta gente.

$\mathrm{O}$ mesmo se diga da zona rectal.

Para Freud e sua escola, o prazer que sentem algumas pessoas pelo acto physiologico da evacuação, cercando-o de commodidades e 
cuidados, dando-lhe a enscenação de um cigarro e de uma revista e mesmo protelando a expulsão das fezes, não é mais do que uma autopederastia, de dentro para fóra.

\section{SONHOS}

O sonho - já se admittia - tem um determinismo e não é um phenomeno sobrenatural.

O que a doutrina de Freud descobre e põe em relevo é o sentido do sonho.

Todo sonho tem um sentido, uma finalidade: é a realização de um desejo, irrealizavel na vigilia.

Todos os impulsos que são recalcados por impossiveis, por immoraes, por inconfessaveis, se realizam no sonho, occasião em que enfraquece a acção da censura.

Ha sonhos simples, como o das creanças, em que a realização do desejo apparece nitida, manifesta, clara, sem subterfugios ou symbolismos, quando a censura é ainda rudimentar.

Todos se lembram de "D. Casmurro" de Machado de Assis. Bentinho, destinado á Igreja por promessa de sua mãe, desespera com a idéa do Seminario, que o ia afastar dos "olhos de resaca" de Capitú.

E sonhou:

"Vi então o Imperador escutando-me, reflectindo e acabando por dizer que sim, que iria falar á minha mãe; eu beijava-lhe a mão, com lagrimas. E logo me achei em casa, á espera, até que ouvi os batedores e o piquete de cavallaria: é o imperador! é o imperador! toda a gente chegava ás janellas para vel-o passar, mas não passava, o coche parava á nossa porta, o imperador apeava-se e entrava.

Grande alvoroço na visinhança "O imperador entrou em casa de D. Gloria! Que será? Que não será?”

A nossa familia saia a recebel-o; minha mãe era a primeira que lhe beijava a mão.

Então o imperador, todo risonho, sem entrar na sala ou entrando - não me lembra bem, os sonhos são muita vez confusos - pedia á minha mãe que não me fizesse padre - e ella, lisongeada e obediente, promettia que não.

- A medicina, porque lhe não manda ensinar a medicina?

- Uma vez que é do agrado de Vossa Magestade.

- Mande ensinar-lhe medicina: é uma bonita carreira, e nós temos aqui bons professores. Nunca foi á nossa Escola? E' uma bella Escola. Já temos medicos de primeira ordem, que podem hombrear com os melhores de outras terras. A medicina é uma grande sciencia: basta só isto de dar saude aos outros, conhecer as molestias, comba- 
tel-as, vencel-as. A Senhora mesmo ha de ter vistos milagres. Seu marido morreu, mas a doença era fatal, e ella não tinha cuidado em si. E' uma bonita carreira; mande-o para a nossa Escola. Faça isso por mim, sim? Você quer, Bentinho?

- Mamãe querendo.

- Quero, meu filho. Sua Magestade manda.

Então, o imperador dava outra vez a mão a beijar, e saia, acompanhado de todos nós, a rua cheia de gente, as janellas atopetadas, um silencio de assombro; o imperador entrava no coche, inclinava-se e fazia um gesto de adeus, dizendo ainda: "A medicina, a nossa Escola" E o coche partia, entre invejas e agradecimentos"

E Machado de Assis conclúe, observalor argutissimo, advinhando Freud:

“- Terás entendido que aquella lembrança do imperador acerca da medicina não era mais que a suggestão da minha pouca vontade de sair do Rio de Janeiro. Os sonhos do accordado são como os outros sonhos tecem-se pelo desenho das nossas inclinações e das nossas recordações" (4)

Mesmo no adulto, em certos casos a realização do desejo é evidente: uma pessoa, p. ex., que se esquece de uma obrigação, esquecimento que acredita involuntario, mas que se origina, na verdade, nas circunstancias desagradaveis que essa obrigação criou, - sonha com o seu adiamento, protelando assim uma occasião desagradavel, sem fugir ao compromisso.

Mas o que succede no adulto é, frequentemente, a complicação de que se revestem os detalhes do sonho, escondendo e mascarando o desejo inconfessavel, de maneira a illudir a vigilancia da censura.

O sonho apparece dessa maneira, absolutamente incomprehensivel, de interpretação apenas accessivel á psychonalyse que lhe estuda o conteúdo manifesto (consciente, que se pode evocar quando se desperta) e o conteúdo latente, refugiado na inconsciencia, com raizes nos complexos. E estuda a psychoanalyse processos geraes do mechanismo onirico, consistentes em symbolização, deslocamento, condensação, todos tendentes ao mascaramento do desejo que se realiza.

Pela psychoanalyse o medico pode, usando do methodo de associação de ideias, auxiliado pela memoria do paciente, chegar até o nucleo central do sonho, encontrado no inconsciente e que seria (para Freud), quasi sempre constituido por um complexo affectivo de essencia sexual.

(4) -Ma hado d: A isis,-- “D. C amurro" 
Translado para aqui a psychoanalyse de um sonho, estudada pelo Dr. Armando Arruda Sampaio e já publicada na nossa "Revista de Medicina"

O facto de já ter sido publicada não lhe tira o sabor original, dada a pequena circulação da Revista. seguinte:

"O sonho escripto por $A$, immediatamente após o despertar é o

"Sonhei que estava sentado num sofá, collocado a um canto de uma pequena sala, separada de outra, maior, por um biombo de madeira.

Ao lado achava-se uma mulher (a que eu chamarei Sra. $X$ ), bonita e bem vestida, cercada de alguns homens que a assediavam com propostas e insinuações a que ella resistia, mostrando-se visivelmente contrariada. Eu, que a conhecia, sentia impetos de soccorre-la, mas não me levantava, acovardado.

A mulher e o grupo de homens que a cercava, dirigiram-se pela porta do biombo que fazia communicar as duas salas, á sala maior, continuando o mesmo cerco e resistencia.

$\mathrm{Eu}$, que me tinha levantado, via, através da porta, a mulher voltando depois de se ter livrado dos homens, os quaes eu via pelas costas, mal os distinguindo num fundo escuro para onde se dirigiam.

Como nos conhecessemos, ella se dirigiu a mim, como a alguem que lhe pudesse valer.

Recebi-a nos braços, disse-lhe algumas palavras amigas, exprobei os homens e, abraçando-a com todas as apparencias de respeito, beijeia na testa.

Este beijo - sentia-o - no sonho - velava uma segunda intensão inconfessavel a respeito da mulher"

Vejamos a psychoanalyse deste sonho feita e descripta pelo Dr. Arruda Sampaio:

"Comecei perguntando ao individuo se havia alguma impressão de vigilia (do mesmo dia ou de dias anteriores) que se pudesse relacionar com o sonho e pedi-lhe tambem todas as associações immediatas que o sonho sugerisse.

Resumo aqui as informações: na mesma noite do sonho, $A$ tinha ido, em companhia de um amigo, a uma pension qualquer. Por varios motivos, não conseguiu dar satisfacção á pensionista, deixando-a sem lhe ter dito ao que ia.

Contou o caso ao amigo, riram, mudaram de assumpto, desvanecendo-se completamente a lembrança do facto, do qual não se lembrou mais no resto da noite.

A sra. X. é uma pessoa das relações de $\mathrm{A}$, a quem este tem em muita consideração. 
Os homens não apparecem muito nitidos e A não denuncia nelles nenhum conhecido ou pessoa de que se possa recordar.

A sala em que se passa a scena, o sofá, em que apparece sentado, e o biombo de madeira, são de uma pensão onde A. morou por pouco tempo.

Note-se, em 1. $0^{\circ}$ lugar, que este sonho é muito simples e muito nitido, desenrolando-se as scenas com muita clareza e ordem, sendo tambem muito nitido o sentimento que A. experimentava em sonho, no qual, como elle mesmo diz na descripção, sentia-se acovardado, não escondendo uma intensão inconfessavel.

Ora, este sentimento não se póde relacionar legitimamente com o facto da vigilia - a frustação de uma.. tentativa?

E' o que parece. Com effeito, o deixar-se um couple sem se ter mostrado uma certa vivacidade, não é dos factos que mais nos exaltem.

Ora, antes do sonho, A. afastou de sua consciencia esse facto desagradavel, pois que delle não se recordou, mais no resto da noite.

Portanto, o individuo em questão recalcou antes do sonho uma idéa humilhante.

Ora, esse sentimento de impotencia que, nem bem surgiu, foi varrido do campo da consciencia, recalcando-se no sub-consciente, apparece nitidamente no sonho que serviu, assim, de valvula de escoamento de sua enegia latente.

Parece que isto, por emquanto, não é forçar as analogias.

Toda idéa desperta um estado d'alma que o individuo procura conservar ou repellir conforme a sua tonalidade affectiva, isto é conforme seja agradavel ou desagradavel. A lembrança de um triumpho, p. ex., embala-nos por muito tempo, ao passo que todos nós procuramos afastar na memoria um feio acto que tenhamos comettido, não admittindo que outros nos venham recorda-lo.

Os estados d'alma ou tendencias que, na vigilia são constrangidos ou repellidos por serem chocantes, ao caracter ou por serem desagradaveis e inopportunos, no sonho se expandem com mais liberdade, pelo afrouxamento do rigor da censura durante o somno a qual todavia não se desvanece de todo.

E' o que se verifica neste sonho, no qual o pacinte assume uma attitude simplesmente inferior: - observa uma senhora cercada de homens que lhe dizem coisas sordidas, quer intervir e se acovarda; depois, recebe-a como amigo e dá-lhe um beijo que mascarava uma segunda intenção.

Note-se este pormenor - que o beijo foi dado na testa - sitio destinado aos beijos paternaes, o que mostra o interesse que tinha $\mathrm{A}$. em dar uma forma respeitosa á sua intenção, pelo prestigio, que, mesmo no sonho, continuava a exercer a Sra. X.; note-se tambem a baixa consideravel que soffreu a sua mentalidade, sob o ponto de vista moral. E' como se vê, um borbulhar muito pouco edificante. 
Vejamos, agora, a significação dos outros elementos.

A Sra. X. é conhecida e respeitada por A. Ella tem, entretanto, motivos para figurar no sonho: é que, mezes antes, A teve que lhe pedir desculpas por não a ter cumprimentado em certa occasião; a lembrança deste facto faz que este elemento - Sra. X - se ligue directamente ao sentimento geral de constrangimento, que domina o sonho.

A., beijando-a, parece que quer realizar uma vingança do que o obrigou o prestigio da dama em questão. Alem disso, sendo X. uma mulher, nada mais razoavel que figure em tal sonho, apezar de nunca ter despertado desejo sexual consciente em A.

Mas por que foi ella e não outra qualquer?

Pela identidade affectiva que a ligava ao resto do conteúdo do sonho, como mostrei acima.

Os personagens masculinos são todos anonymos e talvez não sejam mais que o symbolo da concorrencia. A elles o paciente nada associa de positivo.

O scenario é muito simples. A. reconhece como pertencente a uma pensão onde morou por muito curto prazo, justamente por nella se sentir em desconforto. O scenario lembra, portanto, o mesmo sentimento geral predominante no sonho, o que se dá com todos os outros elementos, que se associaram expontaneamente, por provocarem, uns com maior, outros com menor intensidade, a mesma tonalidade affectiva.

Este sonho tem um fundo nitidamente sexual, o que é muito frequente, e mesmo predominante na genealogia dos sonhos, sem ser, todavia, regra absoluta, pois não ha para Freud, pansexualismo nessa determinação.

Segundo Freud, todo o sonho tem por fim a satisfacção de um desejo. Neste, o facto é typico: $A$ satisfaz o seu desejo sexual, frustado na vespera, beijando a $X$ em sonho, tendo se dado, neste exemplo, a transferencia do desejo de um objecto para outro, transferencia que, junto á dramatização e á condensação, constituem os processos do mechanismo onirico."

O que se disse do processo onirico poderia aclarar, sem duvida, a dynamica do psychismo.

Vejamos, brevemente, o eschema do psychodinamismo, eschema que se encontra em Regis-Hesnard "A psychoanalyse das nevroses e das psychoses: (4).

(4) - - La psychoanalyse des nevroses et des psycioses-F. Alcar--Paris. 

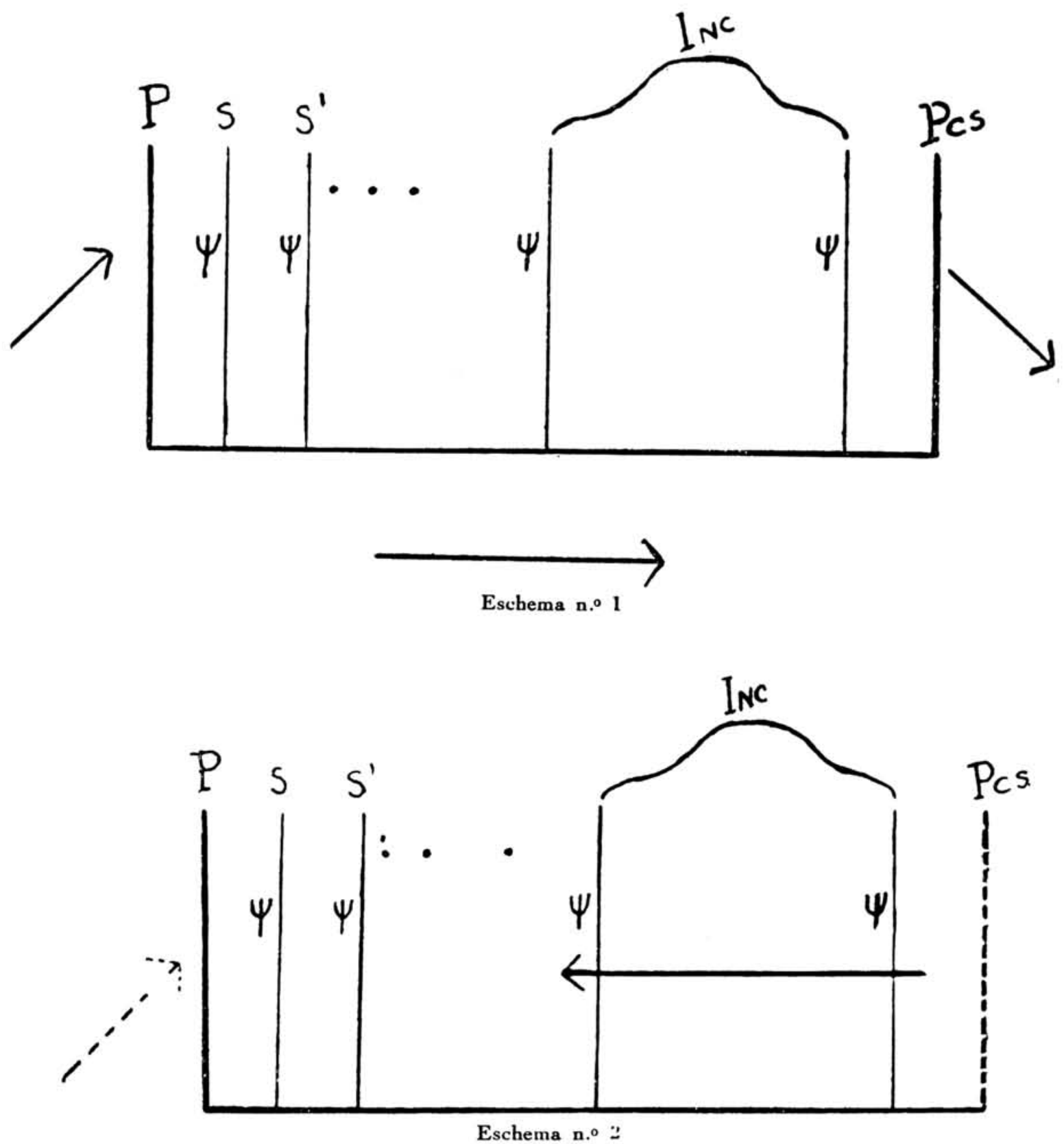

Os elementos do mechanismo psychico são systemas especiaes, submettidos a uma serie de instancias e dispostos segundo uma serie ideal em um sentido determinado que as exitações sensoriomotaras percorrem.

E' facil ver ahi a sua analogia com o acto reflexo elementar.

A excitação parte de $\mathrm{P}$, zona ideal sensorial e segue o sentido da flecha até $M$, onde se dará a resposta motora.

Os elementos inconscientes occupam, como se vê, a parte maior do systema, existindo em todo o psychismo, até a região extrema, Pcs-que é a região do preconsciente, e onde se localiza a censura, que é, na comparação de Freud, um ecran, collocado entre as 2 regiỗes psychicas. 
Das excitações que se succedem ineterruptamente na região sensorial P., restam traços mnesicos, representados no eschema por $\mathrm{S}$, S, S'

A funcção desses traços é a memoria.

Os elementos mnésicos mais proximos de P., estremidade sensorial, reteem os impressões mas não as fixam, continuando aptos a novas percepções; os elementos mais afasctados elaboram essas impressões em traços mnesicos.

Essas systemas de memoria, ligam-sé por associação, uns aos outros, segundo uma ordem immutavel, conforme sua coincidencia no tempo.

O que se deduz facilmente é que todas as excitações que chegam a $P$, seguem, para alcançar $M$, a via mais facil, que é justamente, a mais usada, a de menor resistencia, a que já foi traçada por excitações anteriores.

Carregam-se, portanto, na trajectoria, de numerosas cargas inconscientes e tanto mais fortemente quanto esses elementos se acham mais proximos de $P$ mais recuados na evolução individual, mais antigamente fixados, na infancia, portanto.

Advinha-se pois dahi a influencia consideravel do inconsciente sobre o consciente.

Nos sonhos, a acção da censura enfraquece, o que se representa pela linha pontilhada no eschema n. 2 .

Os elementos inconscientes irrompem, então, na consciencia e, como o seu material é de origem inconsciente, a excitação, em vez de se dirigir de $P$ a $M$, como na vigilia, dirige-se de $M$ a $P$ durante o sonho, isto é, segundo uma via regressiva.

E' por isso que os sonhos se representam, não na forma clara, nitida, consciente, mas na aspecto sensorial, allucinatorio, symbolico, fornecido pelo inconsciente que as aproveita da occasião para se libertar, escapando á censura.

A inspiração, os devaneios, os castellos no ar, teem o mesmo mecanismo psychologico. Do mesmo modo formam-se-sonhos da humanidade as lendas, nas quaes se compraz, milenarmente, a imaginação popular. ciente.

A vida da imaginação encontra seus moveis e motivos no incons-

Os elementos componentes da imaginação, recalcados pelo nivelamento social, procuram sua satisfacção na obra de arte, symbolizando-se para iludirem a censura. 
Eu aconselho, aqui, em parentheses, a quem queira se inteirar perfeitamente do assumpto a leitura da optima these do Dr. Durval Marcondes "O symbolismo estetico em literatura"

As creanças e os selvagens são mais imaginosos que nós: não teem, ainda, a igualar-lhes o psychismo, a plaina da sociedade que faz de todos, um e de um, ninguem.

Queireis um exemplo?

E' de uma historia de Monteiro Lobato:

Bebé gosta mais de um pedaço de sabugo que de todos os seus brinquedos custosos: mais que do automovel que anda sosinho, mais que do trem de 4 vagons, mais que do polichinelo de cubos e de lozangos.

E' que o sabugo, á sua imaginação de creança, pode ser casa, automovel, bruxa, navio. E o polichinelo ha de ser sempre um raio de polichinelo.

Quando a vida imaginativa é por demais intensa que absorve totalmente a attenção do individuo, não chegando mais este a differençal-a da vida real, passamos do terreno normal ao terreno pathologico.

Interessante é tambem dizer aqui, embora rapidamente, o mechanismo psychologico de certos actos, considerados em sua maioria machinaes, insignificantes, mas que possuem, além de um determinismo, um sentido, e, portanto, a maxima importancia em semeiologia mental.

Refiro-me aos lapsos, esquecimentos, distracções, hypotheses, supposições. e muitos outros actos, cujo estudo Freud reuniu sob o titulo de Psychopathologia quotidiana.

$\mathrm{O}$ esquecimento de um nome, que conhecemos perfeitamente, tem sua razão de ser em um obstaculo situado na inconsciencia, que impede a sua pronuncia, porque traz, acompanhando-a, uma serie de circumstancias desagradaveis.

Tenho um amigo que infalivelmente se esquece de certos deveres sociaes, visitas, reuniões, anniversarios apenas porque sua timidez, absolutamente invencivel, recalca as horas e as datas.

Mesmo mechanismo o dos lapsos e distracções. As hypotheses e suposições, são, bem analysadas, realização de um desejo disfarçado. Londres

(5) - Ainda - "Psychoanalysis and oesthetics"-Ch. Baudouin, S. Allen - 
Interessante é o mechanismo atribuido por Freud á formação de certos ditos de espirito. A proposito, cito aqui a psychoanalyse de uma dessas pilherias, feita pelo proprio Freud.

Dois commerciantes que enriqueceram rapidamente, usando meios ilicitos, resolveram, com o fim de serem admittidos em sociedade, dar uma recepção na qual se inauguravam seus retratos pintados a oleo por um artista de fama.

Solicitada a opinião de um critico de arte, este limitou-se a perguntar, apontando o espaço vasio entre os retratos:

- E Jesus onde está?

Esta allusão aos dois ladrões, ladeando o Christo, é um substituto do desprezo que o critico quiz manifestar pelos "nouveaux riches" e que não disse claramente por motivos antagonistas faceis de perceber.

\section{THERAPEUTICA}

Digamos, ligeiramente, a base da therapeutica psychoanalytica.

As observações anotadas por Freud e seu discipulos são tantas e tão concludentes que seria absurdo ir contra essa therapeutica, partindo-se apenas de um ponto de vista theorico.

Aliás, mesmo sob esse aspecto, a explicação do resultado therapeutico é racional:

A nevrose tem origem em uma experiencia desagradavel anterior, em um traumatismo psychico produzido por um recalcamento, em epoca remota do passado individual. A idéa recalcada procura manifestar-se, e manifesta-se de facto, nos symptomas, sua realização disfarçada.

O processo therapeutico tem de procurar o nucleo central da nevrose-o complexo perturbador no inconsciente. E consegue-o, se pacientemente, praticada, pela psycheanalyse.

Para isso esse methodo de exploração mental auxilia-se de todas as manifestações psychicas capazes de levar o observador, por processos auxiliares de associação de idéa, interpreção, etc., até o complexo de origem.

$\mathrm{O}$ paciente, é, então, o collaborador do analysta. $\mathrm{Na}$ analyse dos sonhos, por exemplo, o primeiro deve procurar interpreta-lo, lembrando-se das ideias da vigilia, que quasi sempre constituem o scenario e a idumentaria do sonho, disfarçando-o; o segundo deve estar attento a certos lapsos, distracções e insistir sobre certos detalhes que apparecerem na interpretação, provocando visivel mal estar do paciente.

Qualquer palavra que appareça, assim, com certo esforço ou desagrado do doente, deve ser o ponto de partida de uma associação de idéas, dizendo o paciente em voz alta, livremente, as associações que 
essa palavra conseguir evocar. Ha nesse processo uma abundancia enorme de detalhes que exigem a maxima attenção e a maxima paciencia do medico: certas pausas bruscas na corrente de associação, reluctancia do paciente.

Descoberto, finalmente, o nucleo central perturbador, basta a sua só revelação ao paciente para que se realize a cura.

E' o que se chama methodo cathartico, purgativo.

E a explicação psychologica é facil:

Uma vez que os symptomas da nevrose são a sua maneira exterior, disfarçada, por meio da qual procura a sua realisação a idéa recalcada, basta trazel-a á luz da consciencia, submettendo-a á razão clara, para que cesse a necessidade de mascarar-se.

\section{Encerro aqui a exposição da theoria.}

A um senhor que lhe pedia conselhos quanto á educação de seu filho e que já tinha impertinentemente recusado o estudo das linguas orientaes, do tamul e do malgacho, respondeu, em desespero final, M. Bergeret, professor amavel da Sorbonne: (6)

- Ha, ainda, certa lingua polynesia, que não era mais falada no começo do seculo senão por uma velha mulher amarella. Esta mulher morreu, deixando um papagaio. Um sabio allemão recolheu algumas palavras dessa lingua no bico do papagaio e fez dellas um lexico inteiro. Experimentae essa lingua para o vosso filho.

Prometo-vos desde já que não farei um lexico com o aproveitavel da doutrina de Freud, nas suas applicações extra-medicas. Mas posso affirmar sinceramente, com Jacques Poisson, (7) que um dia os discipulos de Freud estudarão um texto dada com mais proveito para o conhecimento da natureza humana, que um professor de literatura explicando um texto classico.

Até que leiamos esse texto eu vos agradeço immensamente a attenção e peço-vos perdão do roubo do tempo e da paciencia.

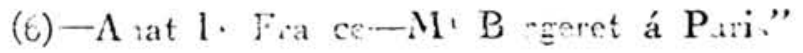

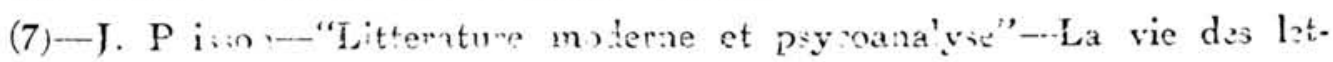
tres et des awts- XVI, P.:.
} 


\section{V.S. jápensou novalor do seu tempo?}
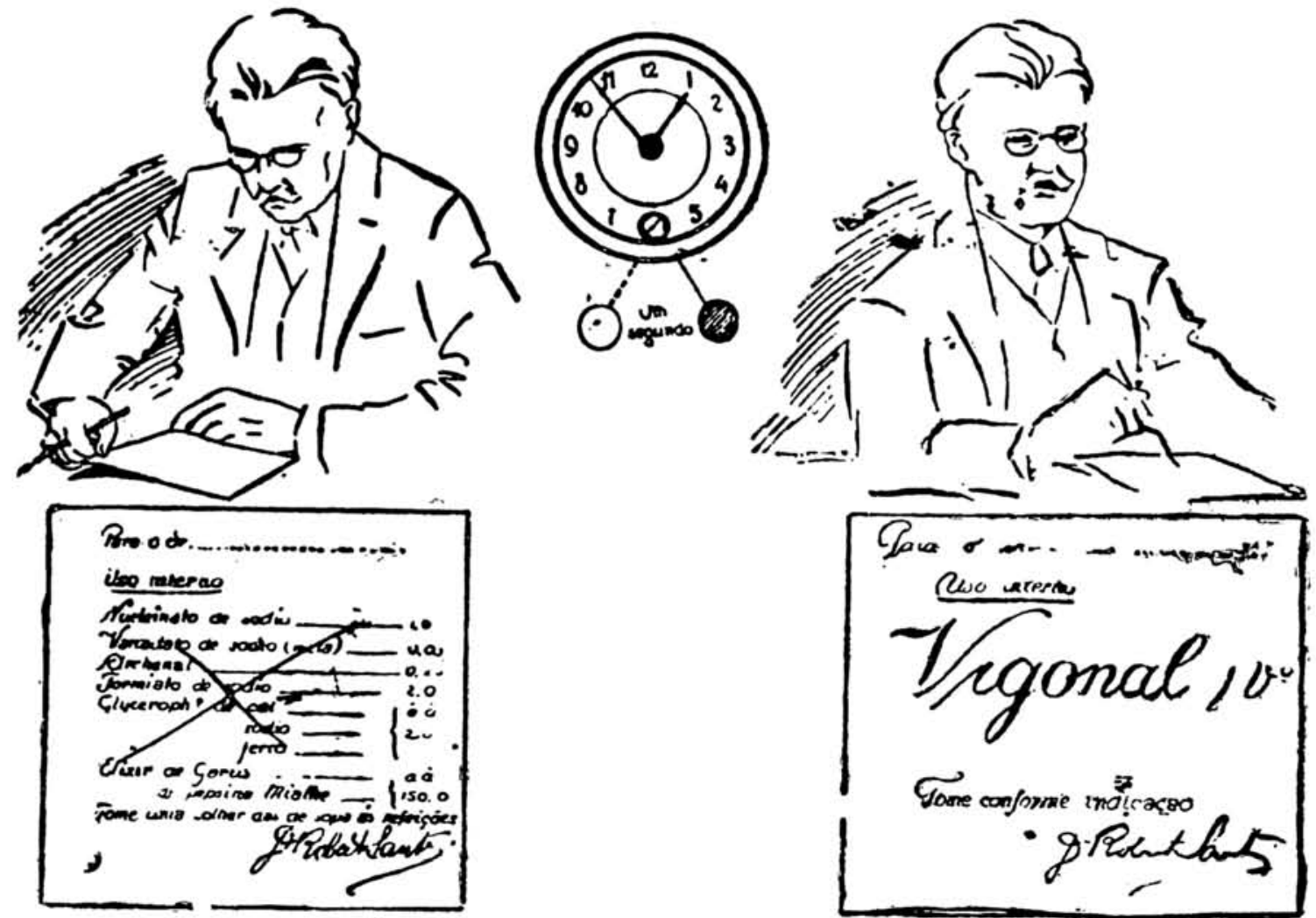

v. S. levaría 5 minutos para formular esta receita.

E m u s e g undo v s. obterá o mesmo resultado.

\section{REFLICTA SENHOR DOUTOR}

O tempo é dinheiro principalmente para o Medico. Porque V. S. ha de perder o seu precioso tempo em formular, quando com uma só palavra, poderá proporcionar ao seu doente um fortificante, cuja formula merece a sua inteira approvação? Receitando "VIGONAL" ao seu cliente elle tomará um remedio manipulado escrupulosamente com drogas de absoluta pureza chimica. Não se esqueça do nome "VIGONAL". Receite hoje mesmo ao primeiro doente que apparecer em seu consultorio e que esteja necessitado de um reconstituinte energico. V. S. não se arrependerá e ficará plenamenie convencido do que acabamos de expôr.

o Doutor tem á sua inteira disposição as amostras gratis que desejar para experimentação. 